Gastroenterologia. 1947;72:I-IV

\title{
Contents, Vol. 72, 1947
}

\section{INDEX}

An unsere Leser - To our readers - A nos lecteurs . . 1

Aufderrnauer,M., Über Pankreasnekrosen ale Folge gene-ralis;erter Arteritis . . . . . . . 81

Baumann,H., Über einfache Eiweißuntersuchungen am

Blutserum 4

Busscher, G. de, La vascuilarisation die 1'estomac ulcéreux 154

Douglas, Ö.M., $\mathrm{C}^{1 / 8}$ ГonicUlce $\Gamma$ of theStomach and Duodenum 145

Finkelstein, Ch., Zur Frage de $\Gamma$ Behandlung des inoperablen

Magenkrebses nut ÜheГtragung vionMagensaft gesunder

Menschen …..... 306

Friedrich,L.v., Der Platz der Gastroskopie in derMagen-

Diagnostik 216

- Ein neues gastroskopisches Symptom beim Zwölffïnger-

darmgeschwü $\quad 299$

Herfort, K., La secretion paiicréatique au gouts de cer-

taine $>\mathrm{s}$ affections hépato-biliaires ..... 51

Hirschberg,F., Untersuchungsbefund und Symptomatolo-gie bei einigen Abdominal-

Erkrankungen . . . 125

Hofstetter,F., pH-Messxmgen mit der Glaiselektrode im

Magensaft ..201

Hotz, H. W'., Hypoproteinämie (Hypalbuminämie) infolge gastro-jejuno-kolischer Fistel ...... 289

Kapp,H., Die Abmagerungskur nach Antoine . . .311

Maratka,Z., Traitement de la côUte uleéreuse par la citrine. Rapport préliminaire

Melchior,E., Zur Chirurgie des Ulcus ventriculi et duo-

deni und des Carcinoma ventriculi . . . .361

Öhnell, H., Chronic Obstipation Usually a Wrong Diagnosisi 383

Starkus, A., Colitis uloerosa Fuso-Spirochaetosa. Bericht

über $3 / 8$ eine infektiöse Form der colitis ulcerosa im deut-

$\beta$ chen Konzentrationslager Stutthof bei Danzig in den

Jahren 1943-1945 35

Troesch,S., Über die biliäre Leberzirrhose ... 96

Kasuistik - Case reports - Casuistique

Lenarl,E., Über gehäuftes gleichzeitiges Auftreten von gutartigen Tumoren am Magein und Zwölffingerdarm 60

Übersîchtsreferate - Reviews - Revues

Bickel,G., Considerations sur les maladies par carence

protéinique 224-316

Montant,R., La resection des nerfs vagues dans l'ulcère 
gastro-duodénal ....... 386

Gesellschaftsberî̀chte - Society Transactions - Sociétés

British Society of Gastroenterolog $1 / 8$ ts. November 1st 1946241

Session de la Socàété ßuisse de Gastro-enitérologie.

Berne, 17 avril 1947341

Editorial

Traitements nouveaux des varices oesophagiennes . . 62

Die Beihandlung des Ulcus mit Gynergen und Dihydro-

eirgotamin

135

Traitement non-opératoire des ulcères perforés . . 260

Referate - Abstracts - Analyses 63, 136, 261, 344, 401

Seite der Therapíe - Page de thérapeutique 76, 283, 417

Buchbesprechangen - Books Review -

Livres Nouveaux $\quad 11,143,285,360,420$

Varht 288 